\title{
Effects of Nano-CaCO$/$ Limestone Composite Particles on the Hydration Products and Pore Structure of Cementitious Materials
}

\author{
Huashan Yang $(D$ and Yujun Che \\ ${ }^{1}$ School of Materials and Architecture Engineering, Guizhou Normal University, Guiyang 550025, China \\ Correspondence should be addressed to Huashan Yang; 13368600935@163.com
}

Received 1 October 2017; Revised 9 December 2017; Accepted 21 December 2017; Published 11 February 2018

Academic Editor: Robert Cerný

Copyright (c) 2018 Huashan Yang and Yujun Che. This is an open access article distributed under the Creative Commons Attribution License, which permits unrestricted use, distribution, and reproduction in any medium, provided the original work is properly cited.

\begin{abstract}
The agglomeration of nano- $\mathrm{CaCO}_{3}(\mathrm{NC})$ is the largest bottleneck in applications in cementitious materials. If nano-CaCO modifies the surface of micron-scale limestone powder (LS), then it will form nano- $\mathrm{CaCO}_{3} /$ limestone composite particles (NC/LS). It is known that micron-scale limestone is easily dispersed, and the "dispersion" of NC is governed by that of LS. Therefore, the dispersion of nano- $\mathrm{CaCO}_{3}$ can be improved by the $\mathrm{NC} / \mathrm{LS}$ in cementitious materials. In this work, the preparation of NC/LS was carried out in a three-necked flask using the $\mathrm{Ca}(\mathrm{OH})_{2}-\mathrm{H}_{2} \mathrm{O}-\mathrm{CO}_{2}$ reaction system. The morphology of NC/LS was observed by a field emission scanning electron microscope (FE-SEM). The effects of NC/LS on the hydration products and pore structure of cementitious materials are proposed. 5\% NC/LS was added into cement paste and mortar, and the mechanical properties of the specimens were measured at a certain age. Differential scanning calorimetry (DSC), thermal gravimetric analysis (TG), and backscattered electron imaging (BSE) were conducted on the specimens to investigate the hydration products and pore structure. The properties of specimens with NC/LS were compared to that of control specimens (without NC/LS). The results revealed that NC/LS reduced the porosity and improved the mechanical properties of the cementitious materials.
\end{abstract}

\section{Introduction}

The development and increasing applications of green highperformance concrete (GHPC) have led to higher requirements for concrete additions, resulting in a variety of mineral additions, such as fly ash (FA), and ground granulated blast-furnace slag (GGBFS) [1-3]. The most successful of these mineral additions, FA, has seen its cost steadily increasing and its availability decreasing. One of the major drawbacks of concrete containing high volumes of FA is known to have negative impact on the early age properties [4]. It significantly slows setting and early-age compressive strength gain. An alternative solution is to use limestone powder (LS).

Considerable research has been carried out in recent years on the use of LS in Portland cement concrete [5-10]. Studies have revealed that limestone powders exhibit a filling effect on concrete [5]. Meanwhile, these powders can react with the aluminium phase in cement paste to create calcium carboaluminate hydrates [11-13] and accelerate $\mathrm{C}_{3} \mathrm{~S}$ hydration
$[14,15]$. In this way, LS can improve the mechanical properties of cement, thus widely applied through various industries. It has been reported that the surface structure is an important property of LS [16]. However, there have been only few published studies concerning the effects of surface structure of LS on the fluidity and strength of Portland cement concrete [17].

In recent years, nano- $\mathrm{CaCO}_{3}$ has been introduced in concrete [18], and some studies have suggested a potential benefit of physical properties of nano- $\mathrm{CaCO}_{3}$ on the development of cementitious system [19-24]. However, it is believed that the most important challenge in the nanocomposite research is to disperse properly the nanomaterials into the matrix $[25,26]$. Due to the high surface energy of nanoparticles, nano- $\mathrm{CaCO}_{3}$ is easy to agglomerate to form secondary particles, which will reduce the properties of cementitious materials. It is believed that nanomicron composite particle is a solution for this question [16]. If nano- $\mathrm{CaCO}_{3}$ grows on the surface of LS, then the nano$\mathrm{CaCO}_{3} /$ limestone composite particles (NC/LS) are prepared. 


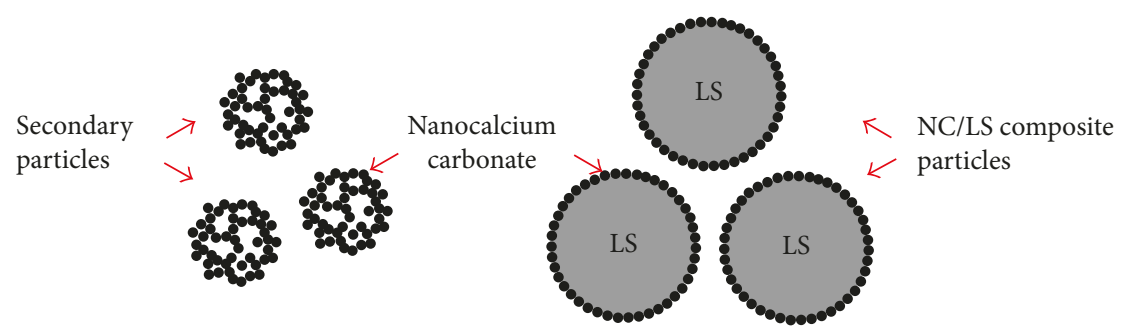

FIGURE 1: Secondary particles and nanomicron composite particles.

As it can be seen from Figure 1, this approach can readily achieve surface modification of LS. NC on the surfaces of LS means that NC is a part of LS. Thus, the "dispersion" of NC is governed by that of LS in cementitious materials. Compared to the nanoparticles, micron-scale LS is easy to obtain better dispersity due to lower surface energy. Therefore, the dispersity of nano- $\mathrm{CaCO}_{3}$ will significantly be improved by NC/LS in cementitious materials. Furthermore, due to the sophisticated surface structures of nanomicron composite particles, it can have a significant effect on the hydration and microstructure of cementitious materials. Camiletti et al. [20] found that nano- $\mathrm{CaCO}_{3}$ accelerates the setting and hardening process of ultra-high-performance concrete through providing nucleation sites, increasing contact points, and increasing the effective water-to-cement ratio. Yang et al. [16] also believes that nano- $\mathrm{CaCO}_{3}$ particles on the surface of LS can act as heterogeneous nuclei for cement paste, making the size of calcium hydroxide crystals smaller, leading to a denser microstructure. Nevertheless, the effects of NC/LS on the hydration products and pore structure of cement pastes have received little attention.

This article explores the effects of NC/LS on the mechanical properties of cement paste and mortar. Differential scanning calorimetry, thermal gravimetric analysis, and backscattered electron imaging were employed to investigate the effects of NC/LS on the hydration products of cementitious materials. Cementitious materials are considered as porous composite materials that consist essentially of a binding medium within which are embedded particles or fragments of aggregate [27]. The complex pore structure of cementitious materials has great significance on their strength, permeability, and durability. The pore structure of cementitious materials was also investigated by BSE images analysis.

\section{Materials and Methods}

2.1. Materials. The materials involved in this study included nano- $\mathrm{CaCO}_{3}$ /limestone composite particles, limestone powder, calcium hydroxide, carbon dioxide, ordinary Portland cement type P.O. 42.5, and ISO standard sand. Carbon dioxide gas with a purity of $99.9 \%$ was purchased from standard commercial sources. Calcium hydroxide, P.O. 42.5 ordinary Portland cement, and ISO standard sand are also commercial products.

Nano- $\mathrm{CaCO}_{3}$ /limestone composite particles were prepared by heterogeneous nucleation. Via changing the reaction parameters such as mixing rate, the morphology of micron-scale limestone particles after coating has been

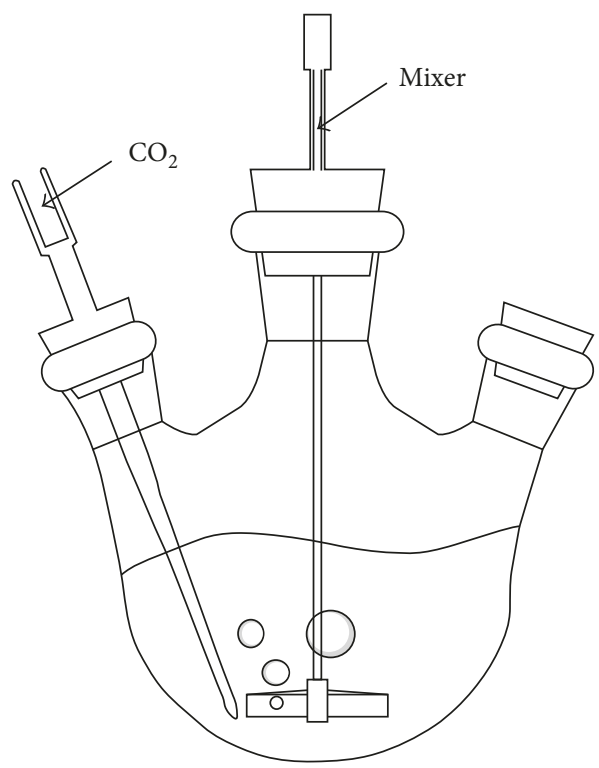

Figure 2: $\mathrm{Ca}(\mathrm{OH})_{2}-\mathrm{H}_{2} \mathrm{O}-\mathrm{CO}_{2}$ reaction system.

altered. The preparation of NC/LS was carried out in a threenecked flask using the $\mathrm{Ca}(\mathrm{OH})_{2}-\mathrm{H}_{2} \mathrm{O}-\mathrm{CO}_{2}$ reaction system (Figure 2). The mixtures comprising limestone powder and saturated solution of calcium hydroxide were stirred at $2400 \mathrm{rpm}$ in a three-necked flask for 10 minutes. Then, carbon dioxide gas was blown into the three-necked flask with the same stirring. The $\mathrm{pH}$ value of the reaction solution was inspected using a $\mathrm{pH}$ meter. When the $\mathrm{pH}$ value reached 6 , the reaction was completed, and then the carbon dioxide flow was stopped. The NC/LS was obtained after the slurry was washed by deionized water, filtered, and dried at $120^{\circ} \mathrm{C}$ in drying oven for at least $24 \mathrm{~h}$. It is reported that some nanoparticles are associated with a high level of toxicity. As shown in Figure 2, the nano- $\mathrm{CaCO}_{3}$ /limestone composite particles were prepared by heterogeneous nucleation in a three-necked flask using the $\mathrm{Ca}(\mathrm{OH})_{2}-\mathrm{H}_{2} \mathrm{O}-\mathrm{CO}_{2}$ reaction system. Nanosized calcium carbonate particles are attached to the surface of micron-scale limestone particles. Also, acute and subchronic toxicity tests were performed to establish the safety of these products after oral administration [28]. Results showed that nano- $\mathrm{CaCO}_{3}$ did not produce any obvious symptoms of toxicity, even at the highest dose administered. Thus, as a raw material of concrete, nano- $\mathrm{CaCO}_{3}$ is safety.

The particle size distribution (PSD) of the LS are presented in Figure 3, which was determined by laser diffraction 


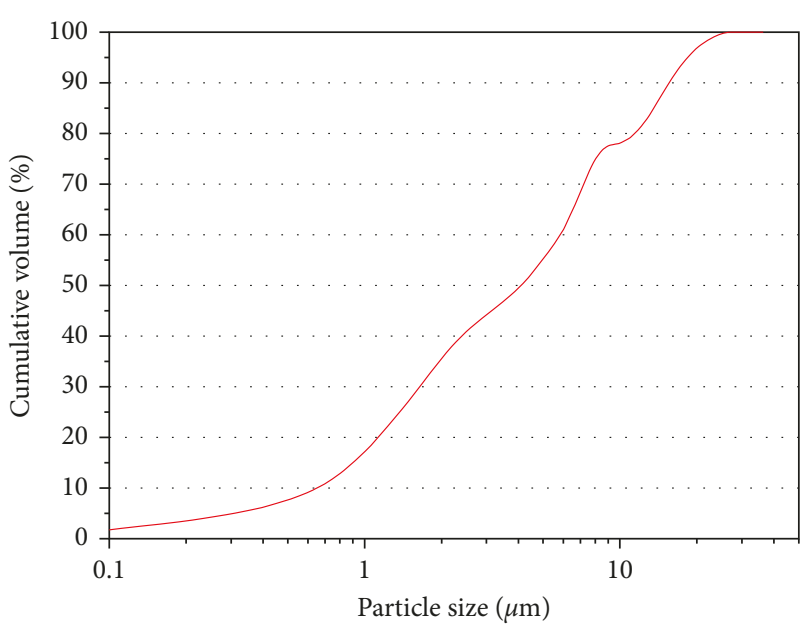

FIgURE 3: PSD of limestone powder.

TABle 1: Chemical composition of cement and limestone (\%).

\begin{tabular}{lcc}
\hline Oxide & Portland cement & Limestone \\
\hline $\mathrm{SiO}_{2}$ & 21.06 & 4.38 \\
$\mathrm{Al}_{2} \mathrm{O}_{3}$ & 6.13 & 1.56 \\
$\mathrm{Fe}_{2} \mathrm{O}_{3}$ & 2.61 & 0.76 \\
$\mathrm{CaO}$ & 61.18 & 48.00 \\
$\mathrm{MgO}$ & 1.66 & 0.49 \\
$\mathrm{~K}_{2} \mathrm{O}$ & 1.06 & 0.14 \\
$\mathrm{Na}_{2} \mathrm{O}$ & 0.21 & 0.03 \\
$\mathrm{SO}_{3}$ & 3.18 & - \\
Loss & 2.12 & 44.17 \\
Others & 0.80 & 0.13 \\
\hline
\end{tabular}

using a laser granulometry (JL-1155, China) for grain size between $0.1 \mu \mathrm{m}$ and $155 \mu \mathrm{m}$. LS has a mean particle size $D_{50}=5 \mu \mathrm{m}$. The chemical composition of Portland cement and LS as given in Table 1 was determined by X-ray fluorescence (XRF). Phase identification of LS was performed at room temperature using X-ray diffraction (XRD, Bruker AXS D8-Focus, Germany) with $\mathrm{Cu}-\mathrm{K} \alpha$ radiation in the range $2 \theta$-scale from $5^{\circ}$ to $65^{\circ}$. X-ray diffraction studies confirmed that the main phase of the LS is calcite (Figure 4).

2.2. Methods. To study the effects of NC/LS on the strength development of cement pastes and mortar, paste mixes were prepared by adopting a water-to-binder ratio of 0.4 , and mortar mixes were prepared by adopting a binder-to-sand ratio of $1: 3$ and water-to-binder ratio of 0.5 . Table 2 summarizes the proportions of cement paste and mortar. Specimens C-0 and $\mathrm{M}-0$ are the control specimens of $\mathrm{C}-\mathrm{NC} / \mathrm{LS}$ and M-NC/LS, respectively. After $24 \mathrm{~h}$, the specimens were demoulded and were immersed in water at $20^{\circ} \mathrm{C}$ until testing. The mechanical properties of these specimens were tested after 3 and 28 days. The test results of cement pastes are the average of three compression test. The test results of cement mortar are the average of three flexural specimens and six compression test. The amount of calcium

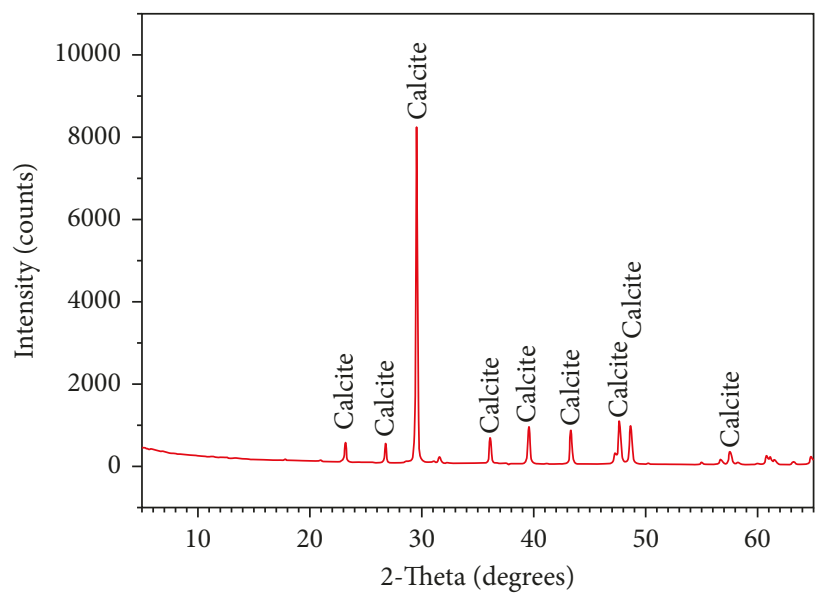

FIGURE 4: XRD pattern of limestone powder.

silicate hydrates and calcium hydroxide present in specimens after 3 days was determined by thermogravimetric analysis (PerkinElmer Instrument, USA) from $100^{\circ} \mathrm{C}$ to $1000^{\circ} \mathrm{C}$ in a nitrogen atmosphere. Samples for DSC-TG analysis were obtained from 3-day-old specimens. Before grinding, specimens were kept in absolute ethyl alcohol up to test to stop the hydration process.

It is believed that pore structure has a direct effect on properties like strength, permeability, and durability of cementitious materials. Mercury intrusion porosimetry (MIP) is a widely used method to characterize the pore structure of cementitious materials. However, the technique has several limitations $[29,30]$, among which are the ink bottle effect and a cylindrical pore geometry assumption that lead to inaccurate pore size distribution curves [31]. Also, Lange et al. [32] compared MIP and image analysis. Results showed that the two methods generate PSD curves of similar shape, and the image-based PSD has the advantage of being able to better describe the large porosity in the microstructure. Therefore, researchers are interested in image analysis for a more complete picture of pore structure. According to the working principles of backscattered electron imaging in scanning electron microscope, the backscattered electrons refer to the incident electrons that are reflected by atoms of the solid sample and the contrast of images are related to the atomic number distribution of sample surface atoms. Areas with high average atomic numbers generate strong signals, resulting in a bright contrast in BSE images. Therefore, the relative atomic number of different areas can be determined based on BSE images contrasts [33].

The partially reacted cement grains, cement hydrates, and pores in concrete are particularly variable, but average features can be measured, which help to understand the microstructure of cementitious materials. A JSM-IT300 scanning electron microscope was used to observe the microstructure of the specimens based on backscattered electron imaging. A small fractured sample was soaked in acetone to stop hydration and dried at $80^{\circ} \mathrm{C}$ for $2 \mathrm{~h}$. Then, the sample was coated with $20 \mathrm{~nm}$ of gold to make it conductive. A magnification of 500x was used for all images. At 500x, the 
TABle 2: Proportions of cement paste and mortar.

\begin{tabular}{lcccc}
\hline Constitute & C-0 & C-NC/LS & M-0 & M-NC/LS \\
\hline Cement paste & & & - & - \\
Water-to-binder ratio & 0.4 & 0.4 & - \\
NC/LS (\%) & 0 & 5.0 & 0.5 & 0.5 \\
Cement mortar & - & - & 0 & 5.0 \\
Water-to-binder ratio & - & - & $1: 3$ & $1: 3$ \\
NC/LS (\%) & - & - & \\
Binder-to-sand ratio & & & \\
\hline
\end{tabular}

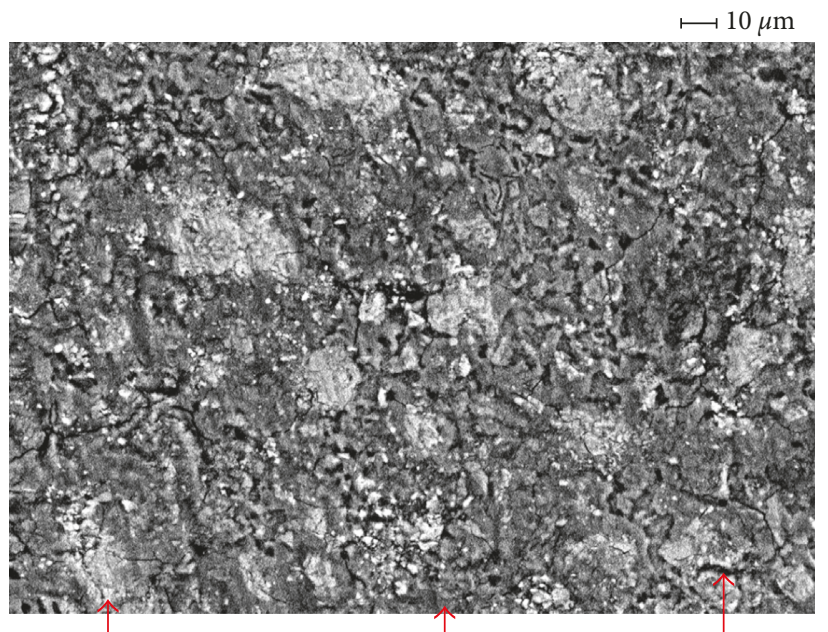

Partially hydrated cement Hydration products

(a)

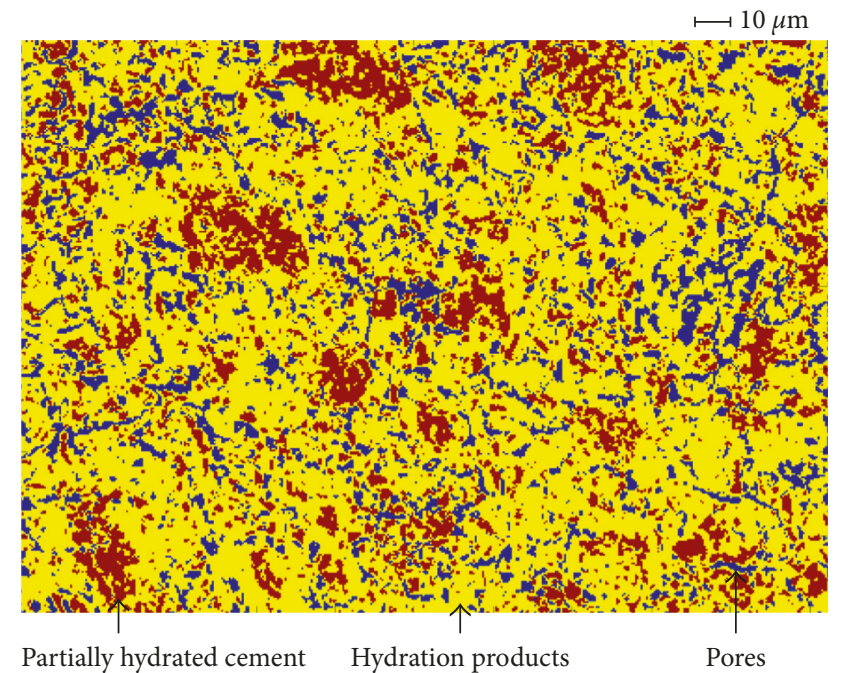

(b)

FIGURE 5: Cluster analysis of partially hydrated cement, hydration products, and pores. (a) A typical BSE image of C-0. (b) Results of cluster analysis.

resolution of the $1024 \times 768$ digital image (width of a single pixel) is $0.222 \mu \mathrm{m}$. Figure 5(a) shows a typical BSE image of specimen C-0. As can be seen, brighter areas correspond to partially reacted cement grains; less bright areas correspond to cement hydrates; and least bright areas correspond to pores. Cluster analysis was conducted on pretreated BSE images to separate partially reacted cement grains, cement hydrates, and pores, as shown in Figure 5(b). The effects of $\mathrm{NC/LS}$ on the pore structure and hydration products of cement specimens can be further investigated by calculating the respective areas of partially reacted cement grains, cement hydrates, and pores, as well as pore size distribution. Ten backscattered electron (BSE) images of random locations on the polished surface of each specimen were captured as image files in the image analysis computer.

\section{Results and Discussion}

3.1. Surface Structure of NC/LS. The micron-scale particles of LS and surface structure of NC/LS are shown in Figure 6(a) and (b), respectively. It is seen that LS is composed of micron-scale particles, which are characterized by smooth cleavage plane and sharp edges. However, the NC/LS, a composite of limestone powder and nanosized calcium carbonate, has very different particle morphology from that of raw limestone particles. As shown in Figure 6(b), nanosized calcium carbonate particles are attached to the surface of micron-scale limestone particles, resulting in a sophisticated surface structure of composite particles. The sharp-pointed edges of the micron-particles are not observed. Tanaka and Koishi [34] and Felekoglu [17] proposed that properties of cementitious materials are not solely related to the particle size distribution, also particle microshape and surface characteristics are important. Thus, the microshape and surface structure of particles have an important effect on the hydration and microstructure of cementitious materials. Furthermore, the most significant issue for nanoparticles is that of effective dispersion [35]. Nano- $\mathrm{CaCO}_{3}$ on the surface of the micron-scale limestone particles will also significantly improve the dispersion of nano- $\mathrm{CaCO}_{3}$ in cementitious materials.

3.2. Strength Development. Figure 7 shows the compressive strength of cement pastes and the flexural and compressive strength of cement mortar after 3 and 28 days. Cement pastes with NC/LS performed better in terms of compressive strength for all ages, probably due to the formation of calcium aluminate monocarbonate and the accelerating 


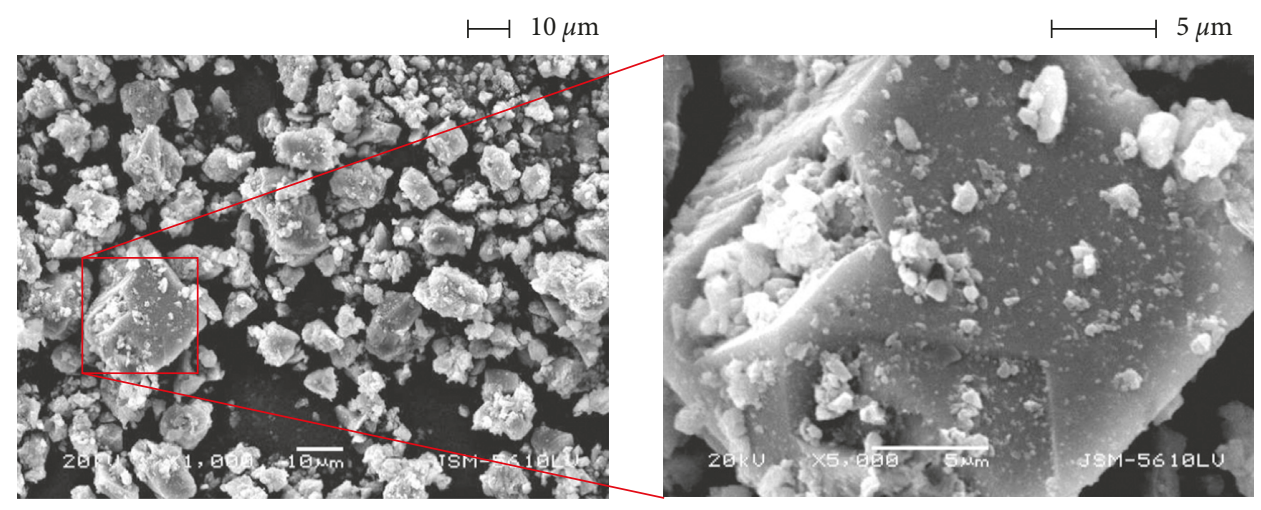

(a)

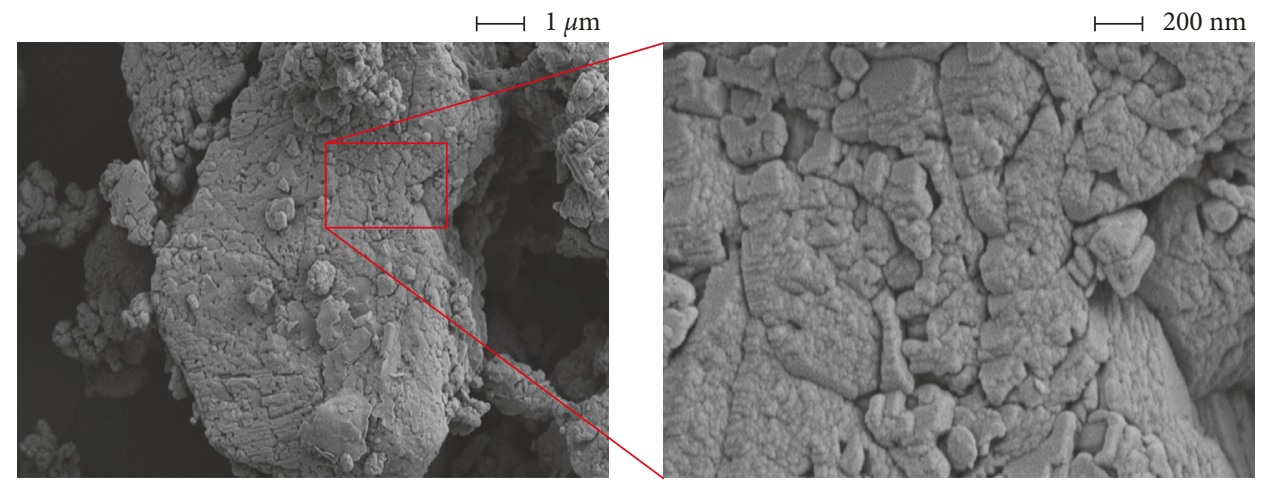

(b)

Figure 6: (a) Micron-scale particles of limestone powder. (b) Surface structure of NC/LS composite particles.

effect on cement hydration in the presence of calcium carbonate $[11,12,14]$. Similarly, the flexural and compressive strength of specimen M-NC/LS was higher than that of specimen M-0. These results suggest that NC/LS improved the mechanical properties of cement paste and mortar. On the other hand, the compressive strength of specimen C-NC/LS after 3 and 28 days was, respectively, $6.3 \%$ and $1.9 \%$ higher than that of specimen $\mathrm{C}-0$. The compressive strength of M-NC/LS after 3 and 28 days was, respectively, $14.5 \%$ and $7.2 \%$ higher than that of M-0. These results indicate that NC/LS improves the cement paste and mortar mechanical properties significantly during the early stages.

As discussed that characteristics of NC/LS are quite different from that of LS and the surface of NC/LS is more favorable for the precipitation and further growth of calcium silicate hydrate gels. Therefore, the improved strength of specimens C-NC/LS and M-NC/LS can be attributed to the complex surface structure of NC/LS, which influenced the size and morphology of hydration products of the cement [16]. Furthermore, XRD results [16] have shown that the complex surface structure of NC/LS can disturb the nucleation and growth of calcium hydroxide, resulting in the reduction of particle size and crystal orientation degree. Furthermore, the nucleation of calcium silicate hydrate is accelerated by the presence of nano- $\mathrm{CaCO}_{3}$ particles [21] because nano- $\mathrm{CaCO}_{3}$ is finer than LS particles. Camiletti, Soliman, and Nehdi also believe that micro- $\mathrm{CaCO}_{3}$ acted mainly as an inert filler, while nano- $\mathrm{CaCO}_{3}$ accelerated the cement hydration process through nucleation, and also acted as an effective filling material [36]. Also, it is reported that the presence of nano- $\mathrm{CaCO}_{3}$ may cause acceleration of early strength development [26], compensates the dilution effect of the binding material, and thus offsets the negative effects of fly ash on early-age properties to facilitate the development of a more environmentally fly ash concrete. Hence, through the use of NC/LS, more environmentally friendly cementitious materials can be produced by reducing its cement factor, while achieving enhanced engineering properties.

3.3. Thermal Gravimetric Analysis. Figure 8 shows the DSCTG curves of specimen C-NC/LS and C-0 after 3 days. It shows the normalized mass loss in percent (current mass divided by initial mass) versus temperature. It can be seen that the two specimens are gradually losing mass with the increasing temperature. The tendency of each curve in varying with the increasing temperature is almost the same. Mass loss between $105^{\circ} \mathrm{C}$ and $420^{\circ} \mathrm{C}$ represents the loss of combined water due to calcium silicate hydrate, aluminate hydrate, and ferroaluminate hydrate, between $420^{\circ} \mathrm{C}$ and $540^{\circ} \mathrm{C}$, it corresponds to the dehydration of calcium hydroxide, and decarbonation of well-crystalline calcium carbonate occurs at temperature between $540^{\circ} \mathrm{C}$ and $750^{\circ} \mathrm{C}$. In Figure 8, three main rapid losses in weight exist in the vicinities of $200^{\circ} \mathrm{C}, 500^{\circ} \mathrm{C}$, and $750^{\circ} \mathrm{C}$ for the two specimens. 


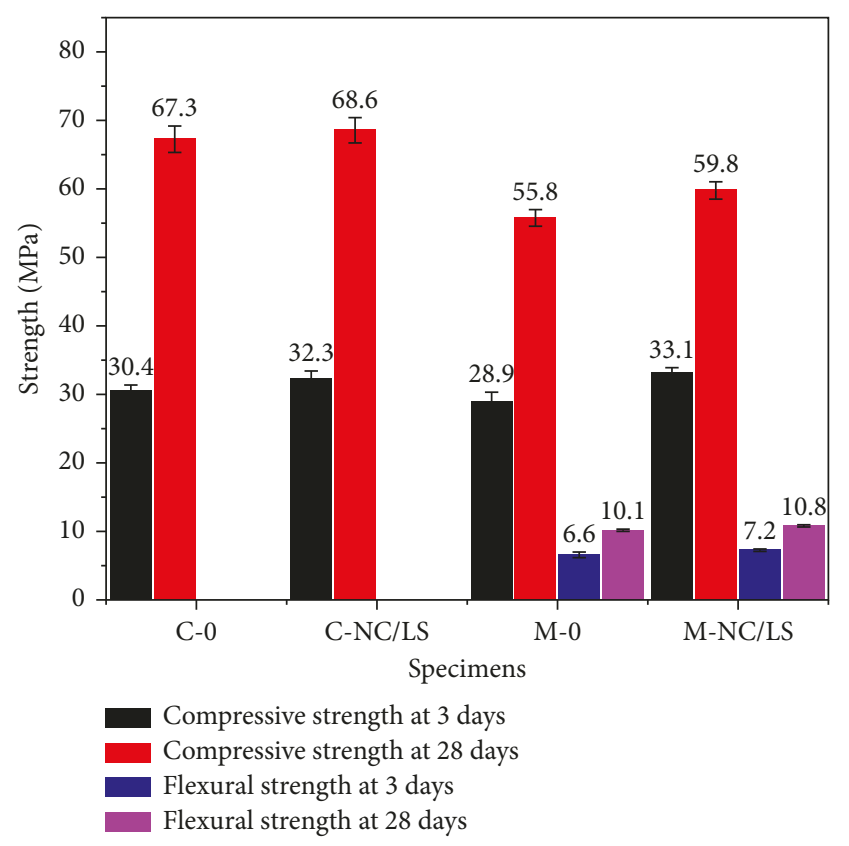

FIgURE 7: Strength of cement paste and mortar with NC/LS.

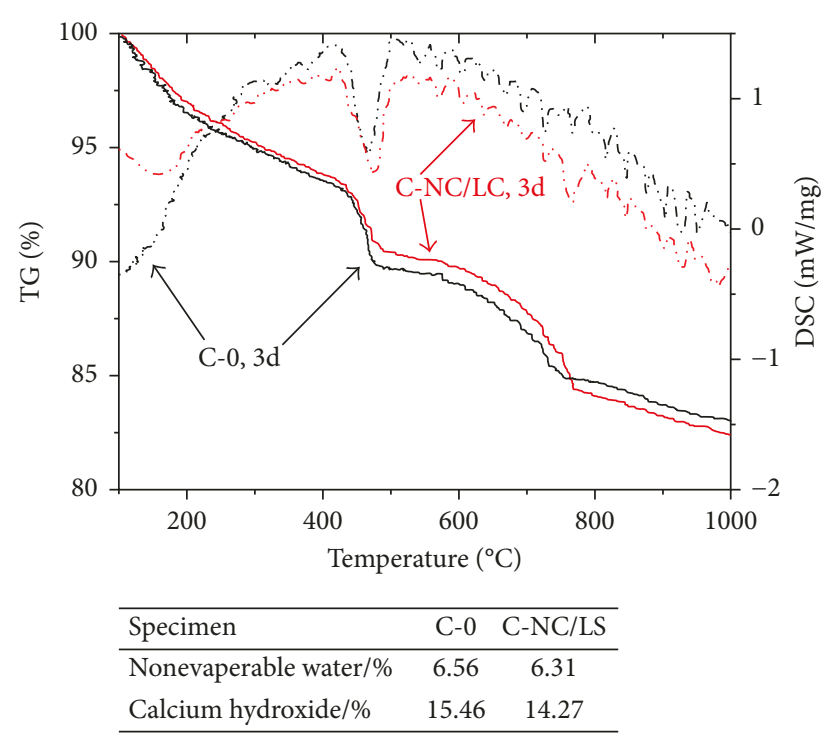

FIGURE 8: DSC-TG curves of specimens.

$\triangle \mathrm{W} 1$ corresponded to the dehydration of calcium silicate hydrates, $\triangle \mathrm{W} 2$ corresponded to the dehydration of calcium hydroxide, and $\triangle \mathrm{W} 3$ corresponded to calcium carbonate decomposition. The $\triangle \mathrm{W} 3$ of specimen C-NC/LS was higher than that of specimen $\mathrm{C}-0$. This can be attributed to calcium carbonate decomposition in NC/LS. The $\triangle \mathrm{W} 1$ and $\triangle \mathrm{W} 2$ of specimen C-NC/LS is slightly lower than that of specimen C-0. This may be due to the part of Portland cement in specimen C-NC/LS which was substituted by NC/LS. On the other hand, the smaller weight loss of calcium hydroxide in specimen C-NC/LS compared to specimen C-0 indicates that the calcium hydroxide absorbs carbon dioxide to form more calcium carbonate probably. However, as shown in
TABLE 3: Porosity and contents of partially reacted cement grain and hydration products calculated based on BSE results.

\begin{tabular}{lcc}
\hline Specimen & C-0 & C-NC/LS \\
\hline Partially reacted cement grain (\%) & 18.6 & 24.2 \\
Hydration products (\%) & 63.5 & 58.5 \\
Porosity (\%) & 17.9 & 17.3 \\
\hline
\end{tabular}

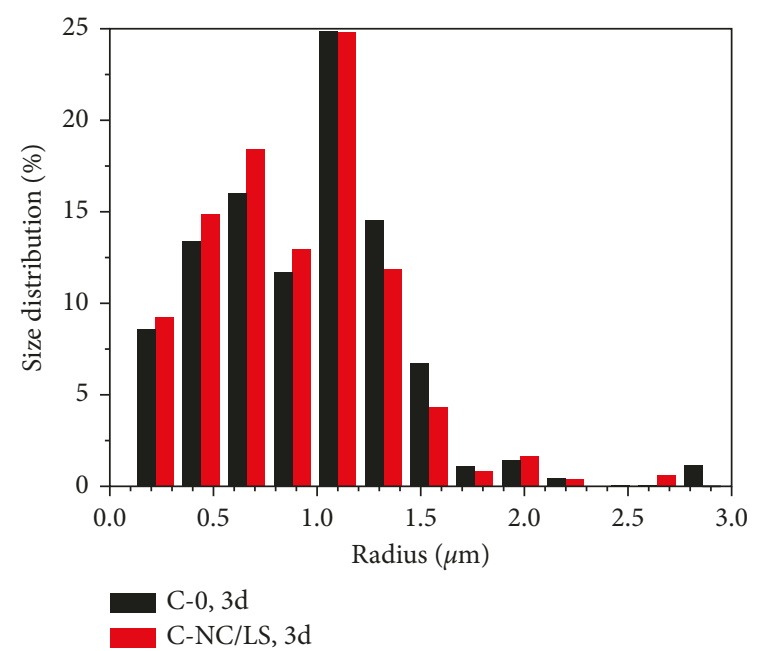

Figure 9: Pore size distributions of specimens.

Figure 7, cement pastes and mortar containing NC/LS exhibited higher strength than that of control specimen at 3 days. The investigation of the phenomenon will be the subject of further research by BSE analysis.

3.4. BSE Image Analysis. Based on BSE images, the contents of partially reacted cement grains and hydration products of different specimens and their respective porosities were calculated and are shown in Table 3. After 3 days, specimen $\mathrm{C}-\mathrm{NC} / \mathrm{LS}$ had higher contents of partially reacted cement grains than that in specimen $\mathrm{C}-0$, and specimen $\mathrm{C}-\mathrm{NC} / \mathrm{LS}$ had lower hydration products content than did specimen C-0. However, the porosity of specimen C-NC/LS was lower than that of specimen C-0. In other words, C-NC/LS had higher structure compactness than that of specimen C-0.

It can be observed from Figure 9 that the larger pores of pastes containing NC/LS are decreased, while the smaller pores are increased. The use of NC/LS leads to a more compact paste with a reduction of larger pores, indicating that the presence of NC/LS is advantageous in pores modification. It is noted that the sophisticated surface structure of NC/LS has a significant influence in decreasing the larger pores of cement pastes and further influences its macroscopic properties [16].

As indicated by both BSE images and DSC-TG results, specimen C-NC/LS had lower contents of calcium silicate hydrate and calcium hydroxide than that in specimen C-0. However, specimen C-NC/LS had higher compressive strength than that of specimen C-0, and specimen M-NC/LS had higher flexural and compressive strength than that of 
specimen M-0. According to further investigations of the porosity and pore structure of specimens obtained, the improved strength of specimens C-NC/LS and M-NC/LS can be attributed to their lower porosity and better pore structure. Hence, the microstructure of cementitious materials with NC/LS depends not only on the distribution of particles but also the morphology and surface structure of the particle. Rashad' research shows that the enhancement in strength of hardened paste is related to the refinement of calcium hydroxide grains, which occurred during the hydration of cement [37]. Thus, the growth of calcium hydroxide grains in cementitious materials may be affected by NC/LS, either.

\section{Conclusions}

Based on the results obtained in this study, the following conclusions can be drawn:

(1) Nano- $\mathrm{CaCO}_{3} /$ limestone composite particles were successfully prepared using the $\mathrm{Ca}(\mathrm{OH})_{2}-\mathrm{H}_{2} \mathrm{O}-\mathrm{CO}_{2}$ reaction system. The surface structure and morphology of micron-scale limestone particles have been altered. Nano- $\mathrm{CaCO}_{3}$ scattered evenly on the surface of the micron-scale limestone particles. It is an effective method to solve the dispersion problem of nano- $\mathrm{CaCO}_{3}$ particles in concrete.

(2) Adding nano- $\mathrm{CaCO}_{3} /$ limestone composite particles resulted in reduced porosity and enhanced pore structure for hardened cementitious materials. The microstructure of hardened cementitious materials was optimized by nano- $\mathrm{CaCO}_{3} /$ limestone composite particles. Therefore, the mechanical properties of cement paste and mortar were improved.

\section{Conflicts of Interest}

The authors declare that there are no conflicts of interest regarding the publication of this paper.

\section{Acknowledgments}

This work is supported by the National Natural Science Foundation of China under 51669004, and the Hubei Natural Science Foundation of China under 2014CFB705.

\section{References}

[1] P. C. Aitcin, "Cements of yesterday and today: concrete of tomorrow," Cement and Concrete Research, vol. 30, no. 9, pp. 1349-1359, 2000.

[2] E. Gartner, "Industrially interesting approaches to "low- $\mathrm{CO}_{2}$ " cements," Cement and Concrete Research, vol. 34, no. 9, pp. 1489-1498, 2004.

[3] P. K. Mehta and R. W. Burrows, "Building durable structures in the 21st century," Concrete International, vol. 23, no. 3, pp. 57-63, 2001.

[4] S. Kawashima, J. W. T. Seo, D. Corr, M. C. Hersam, and S. P. Shah, "Dispersion of $\mathrm{CaCO}_{3}$ nanoparticles by sonication and surfactant treatment for application in fly ash-cement systems," Materials and Structures, vol. 47, no. 6, pp. 10111023, 2014.

[5] V. Bonavetti, H. Donza, G. Menendez, O. Cabrera, and E. F. Irassar, "Limestone filler cement in low w/c concrete: a rational use of energy," Cement and Concrete Research, vol. 33, no. 6, pp. 865-871, 2003.

[6] A. A. Elgalhud, R. K. Dhir, and G. Ghataora, "Limestone addition effects on concrete porosity," Cement and Concrete Composites, vol. 72, pp. 222-234, 2016.

[7] M. Heikal, H. El-Didamony, and M. S. Morsy, "Limestonefilled pozzolanic cement," Cement and Concrete Research, vol. 30, no. 11, pp. 1827-1834, 2000.

[8] S. Palm, T. Proske, M. Rezvani, S. Hainer, C. Muller, and C. A. Graubner, "Cements with a high limestone contentmechanical properties, durability and ecological characteristics of the concrete," Construction and Building Materials, vol. 119, pp. 308-318, 2016.

[9] S. Tsivilis, E. Chaniotakis, G. Kakali, and G. Batis, "An analysis of the properties of Portland limestone cements and concrete," Cement and Concrete Composites, vol. 24, no. 3-4, pp. 371-378, 2002.

[10] N. Voglis, G. Kakali, E. Chaniotakis, and S. Tsivilis, "Portlandlimestone cements. Their properties and hydration compared to those of other composite cements," Cement and Concrete Composites, vol. 27, no. 2, pp. 191-196, 2005.

[11] V. L. Bonavetti, V. F. Rahhal, and E. F. Irasser, "Studies on the carboaluminate formation in limestone filler-blended cements," Cement and Concrete Research, vol. 31, no. 6, pp. 853-859, 2001.

[12] G. Kakali, S. Tsivilis, E. Aggeli, and M. Bati, "Hydration products of $\mathrm{C}_{3} \mathrm{~A}, \mathrm{C}_{3} \mathrm{~S}$ and Portland cement in the presence of $\mathrm{CaCO}_{3}$," Cement and Concrete Research, vol. 30, no. 7, pp. 1073-1077, 2000.

[13] B. Lothenbach, G. Le Saout, E. Gallucci, and K. Scrivener, "Influence of limestone on the hydration of Portland cements," Cement and Concrete Research, vol. 38, no. 6, pp. 848-860, 2008.

[14] J. Pera, S. Husson, and B. Guilhot, "Influence of finely ground limestone on cement hydration," Cement and Concrete Composites, vol. 21, no. 2, pp. 99-105, 1999.

[15] V. Rahhal and R. Talero, "Early hydration of Portland cement with crystalline mineral additions," Cement and Concrete Research, vol. 35, no. 7, pp. 1285-1291, 2005.

[16] H. Yang, Y. Che, and M. Zhang, "Effect of nano- $\mathrm{CaCO}_{3} /$ limestone powder composite on the early age cement hydration products," Key Engineering Materials, vol. 703, pp. 354-359, 2016.

[17] B. Felekoglu, "Effects of PSD and surface morphology of micro-aggregates on admixture requirement and mechanical performance of micro-concrete," Cement and Concrete Composites, vol. 29, no. 6, pp. 481-489, 2007.

[18] F. U. A. Shaikh and S. W. M. Supit, "Mechanical and durability properties of high volume fly ash (HVFA) concrete containing calcium carbonate $\left(\mathrm{CaCO}_{3}\right)$ nanoparticles," Construction and Building Materials, vol. 70, pp. 309-321, 2014.

[19] F. U. A. Shaikh and S. W. M. Supit, "Chloride induced corrosion durability of high volume fly ash concretes containing nano particles," Construction and Building Materials, vol. 99, pp. 208-225, 2015.

[20] J. Camiletti, A. M. Soliman, and M. L. Nehdi, "Effect of nanocalcium carbonate on early-age properties of ultra-highperformance concrete," Magazine of Concrete Research, vol. 65, no. 5, pp. 297-307, 2013. 
[21] T. Sato and J. J. Beaudoin, "Effect of nano- $\mathrm{CaCO}_{3}$ on hydration of cement containing supplementary cementitious materials," Advances in Cement Research, vol. 23, no. 1, pp. 33-43, 2011.

[22] S. Kawashima, P. K. Hou, D. J. Corr, and S. P. Shah, "Modification of cement-based materials with nanoparticles," Cement and Concrete Composites, vol. 36, pp. 8-15, 2013.

[23] J. M. Makar, G. W. Chan, J. J. Beaudoin, F. Torres, and K. Trischuk, "Effect of $\mathrm{n}-\mathrm{CaCO}_{3}$ and metakaolin on hydrated Portland cement," Advances in Cement Research, vol. 24, no. 4, pp. 211-219, 2012.

[24] G. C. Long, Y. Shi, K. L. Ma, and Y. J. Xie, "Reactive powder concrete reinforced by nanoparticles," Advances in Cement Research, vol. 28, no. 2, pp. 99-109, 2016.

[25] A. H. Korayem, N. Tourani, M. Zakertabrizi, A. M. Sabziparvar, and W. H. Duan, "A review of dispersion of nanoparticles in cementitious matrices: nanoparticle geometry perspective," Construction and Building Materials, vol. 153, pp. 346-357, 2017.

[26] T. Meng, Y. Yu, and Z. Wang, "Effect of nano- $\mathrm{CaCO}_{3}$ slurry on the mechanical properties and micro-structure of concrete with and without fly ash," Composites Part B: Engineering, vol. 117, pp. 124-129, 2017.

[27] S. W. Tang, X. H. Cai, Z. He et al., "The review of pore structure evaluation in cementitious materials by electrical methods," Construction and Building Materials, vol. 117, pp. 273-284, 2016.

[28] S. Huang, J. C. Chen, C. W. Hsu, and W. H. Chang, "Effects of nano calcium carbonate and nano calcium citrate on toxicity in ICR mice and on bone mineral density in an ovariectomized mice model," Nanotechnology, vol. 20, no. 37, pp. 1-7, 2009.

[29] S. Diamond, "Mercury porosimetry: an inappropriate method for the measurement of pore size distributions in cementbased materials," Cement and Concrete Research, vol. 30, no. 10, pp. 1517-1525, 2000.

[30] K. Tanaka and K. Kurumisawa, "Development of technique for observing pores in hardened cement paste," Cement and Concrete Research, vol. 32, no. 9, pp. 1435-1441, 2002.

[31] K. L. Willis, A. B. Abell, and D. A. Lange, "Image-based characterization of cement pore structure using wood's metal intrusion," Cement and Concrete Research, vol. 28, no. 12, pp. 1695-1705, 1998.

[32] D. A. Lange, H. M. Jennings, and S. P. Shah, "Image-analysis techniques for characterization of pore structure of cementbased materials," Cement and Concrete Research, vol. 24, no. 5, pp. 841-853, 1994.

[33] K. L. Scrivener, "Backscattered electron imaging of cementitious microstructures: understanding and quantification," Cement and Concrete Composites, vol. 26, no. 8, pp. 935-945, 2004.

[34] I. Tanaka and M. Koishi, "Fundamental properties of powder, paste and mortar of surface modified cement and process of the surface modification," Construction and Building Materials, vol. 13, no. 5, pp. 285-292, 1999.

[35] F. Pacheco-Torgal, S. Miraldo, Y. Ding, and J. A. Labrincha, "Targeting HPC with the help of nanoparticles: an overview," Construction and Building Materials, vol. 38, pp. 365-370, 2013.

[36] J. Camiletti, A. M. Soliman, and M. L. Nehdi, "Effects of nanoand micro-limestone addition on early-age properties of ultra-high-performance concrete," Materials and Structures, vol. 46, no. 6, pp. 881-898, 2013.

[37] A. M. Rashad, "Effects of $\mathrm{ZnO}_{2}, \mathrm{ZrO}_{2}, \mathrm{Cu}_{2} \mathrm{O}_{3}, \mathrm{CuO}, \mathrm{CaCO}_{3}$, $\mathrm{SF}, \mathrm{FA}$, cement and geothermal silica waste nanoparticles on properties of cementitious materials-a short guide for civil engineer," Construction and Building Materials, vol. 48, pp. 1120-1133, 2013. 


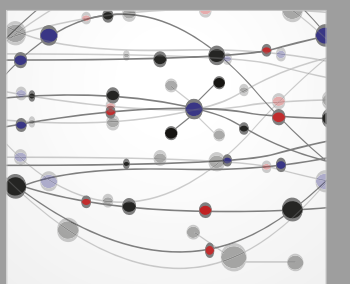

The Scientific World Journal
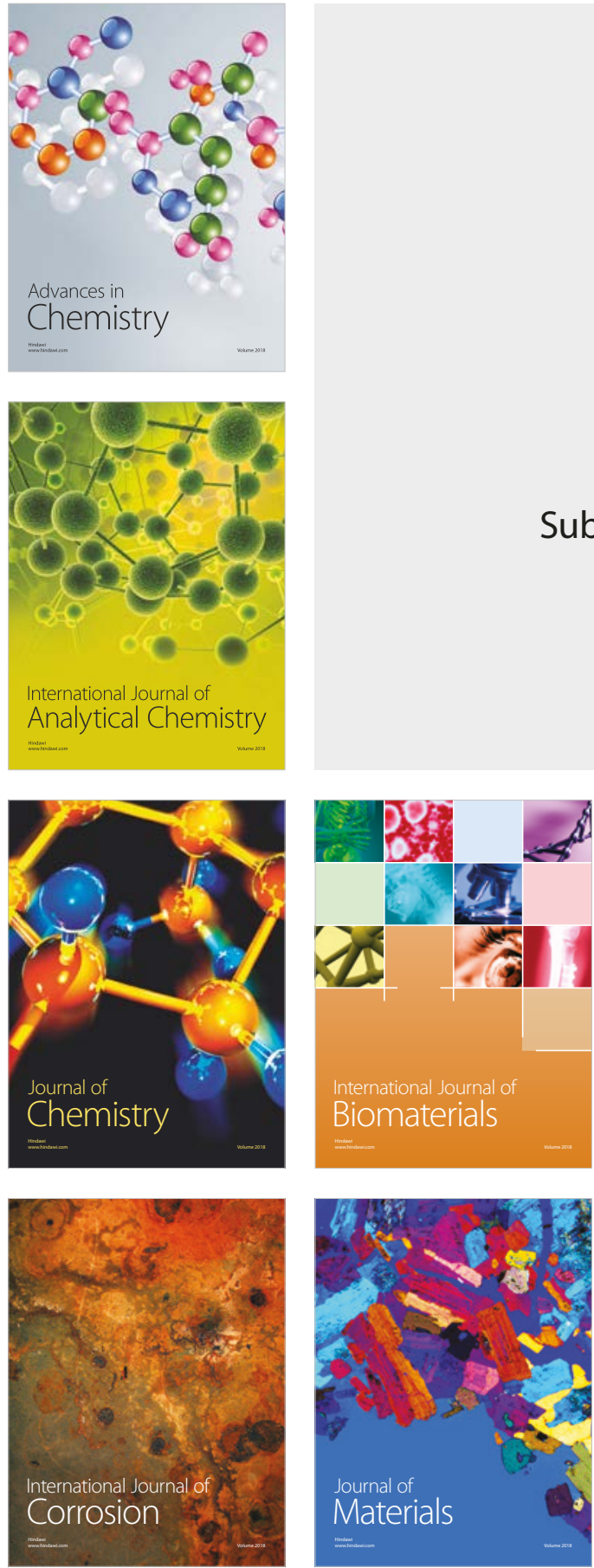

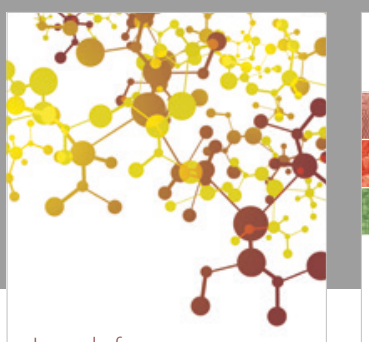

Journal of

Applied Chemistry
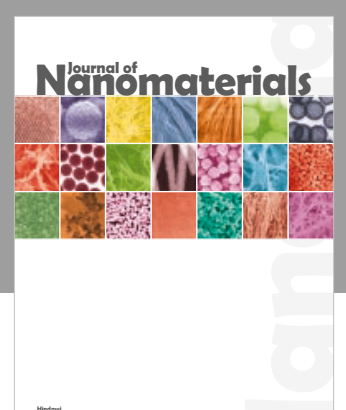

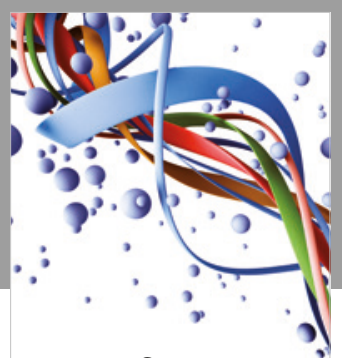

Scientifica

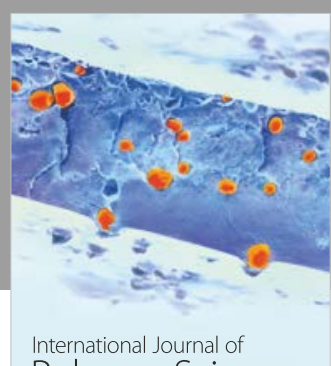

Polymer Science

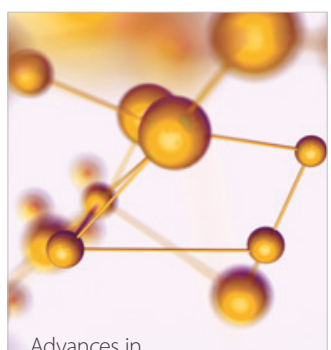

Physical Chemistry
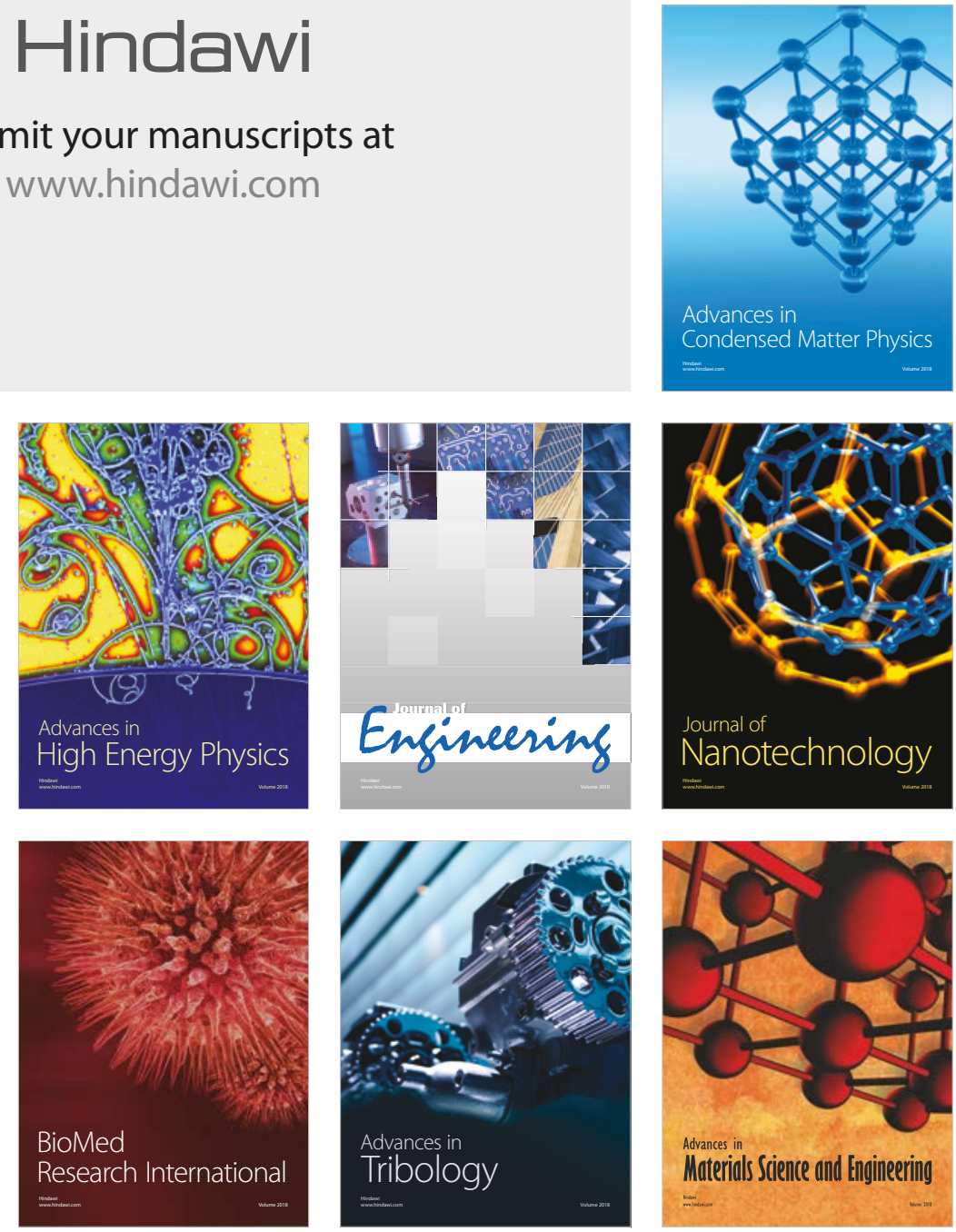